\title{
Insulin and EGF Receptors Integrate the Ras and Rap Signaling Pathways
}

\author{
JEFFREY E. PESSIN AND SHUICHI OKADA \\ Department of Physiology and Biophysics The University of Iowa, Iowa City, IA 52242-1109, USA
}

\begin{abstract}
Ras is a low molecular weight (Mr 21,000) GTP binding protein that plays an essential role in cell proliferation and differentiation. Mutations that result in constitutive activation of Ras are associated with several types of neoplastic tissue in mammals and expression of these alleles into cultured fibroblasts results in cellular transformation. Opposing the Ras activation pathway, the low molecular GTP binding protein Rap was originally observed to revert or suppress the transformed phenotype in Ki-Ras-transformed fibroblasts. This apparent antagonism between Ras and Rap function may reflect the ability of Rap and Ras to interact with the same downstream effectors, since these proteins share identical sequences within their respective effector domains. Although the precise molecular details remained to be established, there is a substantial similarity in the upstream signaling mechanisms that regulate both Ras and Rap activation. Ras GTP binding is stimulated upon the targeting of the Ras guanylnucleotide exchange factor SOS to the plasma membrane location of Ras. The carboxyl terminal domain of SOS contains a proline-rich regions that directs its association with the SH3 domains of the small adapter protein, Grb2. Similarly, the formation of active GTP-bound Rap results from the specific interaction with the Rap guanylnucleotide exchange factor C3G which specifically associates with the central SH3 domain of the small adapter protein, CrkII. Thus, efficient regulation of receptor tyrosine kinase downstream signaling events require the coordinate interplay of these two pathways.
\end{abstract}

Key words: Ras, Rap, Tyrosine kinase, Insulin, Epidermal growth factor

(Endocrine Journal 46: S11-S16, 1999)

LOW molecular weight GTP binding proteins play essential roles as molecular switches controlling diverse processes including cytoskeleton organization, intracellular vesicular trafficking, protein translocation, macromolecular biosynthesis, entry into the cell cycle and mitogenesis $[1,2]$. The prototypical small GTP binding protein, Ras, is a $21 \mathrm{kDa}$ membrane anchored protein that was originally identified as an oncogene in human bladder, lung and colon carcinomas [3-5]. The best characterized proximal downstream Ras target is the Raf1 serine/threonine kinase which specifically associates with GTP-bound Ras [6-10]. The interaction of Raf1 with Ras results the activation

Correspondence to: Dr. Jeffrey E. PESSIN, Department of Physiology and Biophysics, The University of Iowa, Iowa City, IA 52242-1109, USA of the Raf1 protein kinase activity which in turn phosphorylates and activates the dual functional protein kinase, termed MEK [11-15]. This kinase phosphorylates the ERK family of MAP kinases on both threonine and tyrosine residues in a characteristic TEY motif. The subsequent activation of ERK provides an important bifurcation point for the stimulation of numerous signaling pathways including metabolic, transcriptional and mitogenic events [16-19].

Opposing the Ras activation pathway, the low molecular GTP binding protein Rap was originally observed to revert or suppress the transformed phenotype in Ki-Ras-transformed fibroblasts [20, 21]. Although Rap can function as a positive regulatory of the Raf/MEK/ERK cascade in certain cell contexts, in multiple cell types several studies have demonstrated that Rap can function as a 
suppresser of Ras-mediated downstream signaling. For example, both Ras and T-antigen dependent transformation can be reversed by Rap1 expression [20, 22]. In addition, constitutively active Rap1 prevents Ras-induced germinal vesicle breakdown in Xenopus oocytes and in mammalian cells antagonizes the Ras-dependent activation of the MAP kinase pathway, c-fos gene expression and the Ras-mediated inhibition of muscarinic potassium channel activity [23-26]. This apparent antagonism between Ras and Rap function may reflect the ability of Rap and Ras to interact with the same downstream effectors since they share identical sequences within their respective effector domains [20, 21, 27-31]. Consistent with this concept of effector competition, the association of Raf1 with GTP-bound Ras results in the activation of Raf1 protein kinase activity whereas the association with GTP-bound Rap results in an inhibition of Raf1 protein kinase activity [32].

In addition to the similarity in downstream signaling pathways, the mechanisms that regulate both Ras and Rap activation are highly related. Ras GTP binding is stimulated upon the targeting and/or activation of the Ras guanylnucleotide exchange factor SOS [33-36]. The carboxyl terminal domain of SOS contains a proline-rich regions that direct its association with the $\mathrm{SH} 3$ domains of the small adapter protein, Grb2 [37-42]. In analogy, the central SH3 domain of the small adapter protein CrkII associates with the proline rich regions of Rap guanylnucleotide exchange factor C3G [4346]. Similar to Grb2, Crk represents another family of small adapter proteins that are comprised of $\mathrm{SH} 2$ and SH3 domains [47-50]. CrkII is composed of a single amino terminal $\mathrm{SH} 2$ domain and two tandem SH3 domains. Under basal conditions, the Rap guanylnucleotide exchange factor C3G is associated with CrkII through interactions between the central $\mathrm{SH} 3$ domain of CrkII with several proline rich regions in C3G [44-46, 51].

Recently we and others have demonstrated that the activation of Ras can be limited by a negative feedback loop which results in the serine/threonine phosphorylation of SOS [52-55]. This phosphorylation event appears to coincide with the dissociation of the Grb2-SOS complex and desensitization of Ras as measured by the amount of GTP versus GDP bound to immunoprecipitated Ras protein. These data suggest a model in which enhanced SOS activity is maintained until the Grb2-

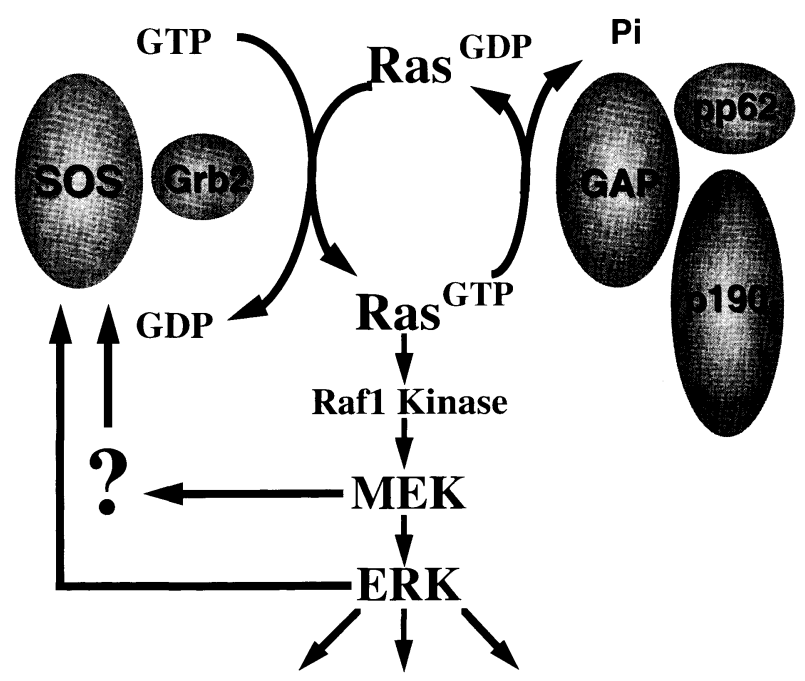

Fig. 1. Schematic model for the activation/inactivation GTP/GDP cycle of Ras. In the basal state, Ras predominantly exists in the inactive GDP-bound state due to the GTPase activity of GAP. However, following growth factor stimulation the guanylnucleotide exchange factor SOS becomes targeted to and/or becomes activated toward Ras, resulting in the exchange of GDP for GTP. Once Ras is in the active GTP-bound state it associates and activates the Raf1 serine kinase which in turn phosphorylates and activates MEK. MEK then phosphorylates ERK which can then phosphorylate and activate a variety of cytosolic and nuclear factors. In addition, either ERK and/or another MEK-dependent kinase phosphorylates SOS which reduces its affinity for Grb2. The dissociation of the Grb2-SOS complex then inhibits any further Ras activation allowing GAP to restore Ras back to the inactive GDP-bound state.

SOS complex dissociates causing either decreased nucleotide exchange activity or prevention of the targeting of SOS to the plasma membrane location of Ras (Fig. 1).

Based upon the antagonistic function of Rap, we would expect that there also exists a cellular mechanism for the inactivation of Rap. We therefore hypothesized that a more proximal signaling pathway leading to the dissociation of CrkII from C3G may also exist to inactivate Rap prior to the activation of the Ras/Raf/MEK/ERK pathway. To explore this possibility, we have recently observed a rapid ( $<1 \mathrm{~min})$ insulin or EGF stimulated dissociation of the CrkII-C3G complex (Fig. 2). In unstimulated cells, immunoprecipitation of C3G resulted in the co-immunoprecipitation of CrkII (Fig. 2A, lane 1). However, following insulin 
A) Insulin

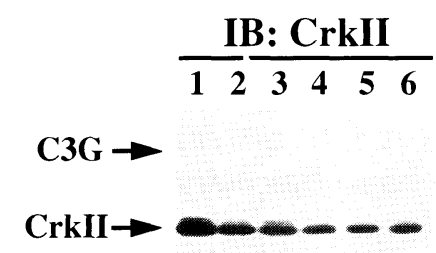

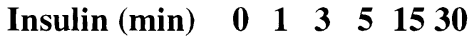

B) EGF

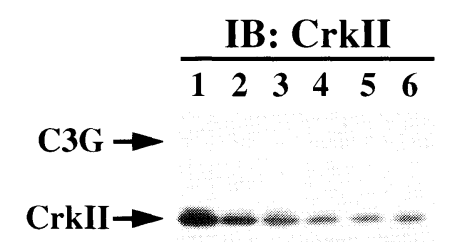

$\begin{array}{llllllll}\text { EGF (min) } & 0 & 1 & 3 & 5 & 15 & 30\end{array}$

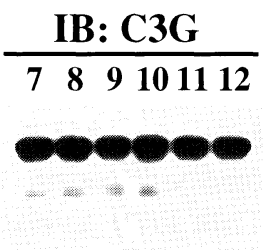

$\begin{array}{lllllll}0 & 1 & 3 & 5 & 15 & 30\end{array}$

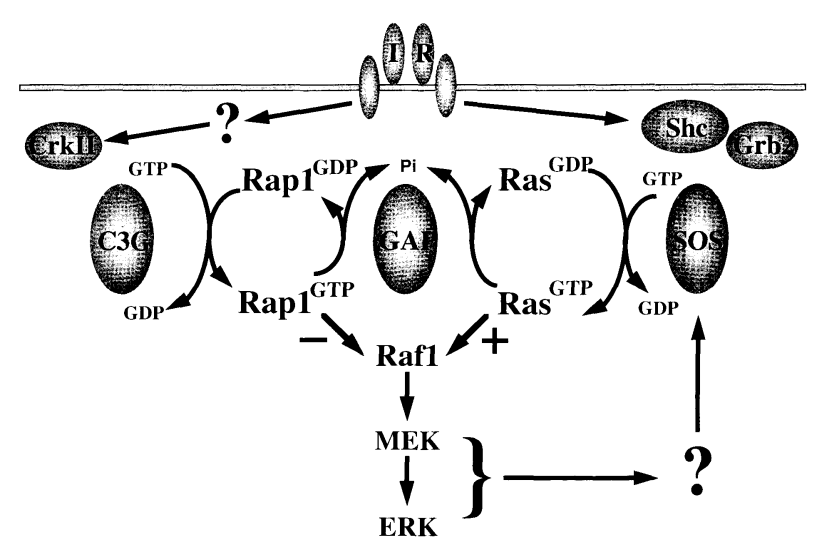

Fig. 3. Hypothesized model depicting the predicted relationship between the Ras and Rap GTP cycles. In this model, activation of growth factor receptors (in this case the insulin receptor) induces the tyrosine phosphorylation of Shc and thereby generates the formation of the Shc-Grb2-SOS ternary complex necessary for Ras activation. In parallel, the insulin receptor stimulates the tyrosine phosphorylates CrkII inducing the dissociation of the CrkII-C3G complex and the inactivation of Rap. Inactivation of Rap allows Raf1 to associate with Ras and its subsequent activation results in the stimulation of the ERK kinase cascade.

Fig. 2. Insulin and EGF stimulation result in the dissociation of the CrkII-C3G complex. A) Chinese hamster ovary cells engineered to over express both the human insulin and EGF receptors (CHO/IR/ER) were incubated in the absence (lanes 1 and 7) or in the presence of $100 \mathrm{nM}$ insulin for 1 (lanes 2 and 8), 3 (lanes 3 and 9), 5 (lanes 4 and 10), 15 (lanes 5 and 11) and 30 (lanes 6 and 12) $\min$ at $37^{\circ} \mathrm{C}$. B) CHO/IR/ER cells were incubated in the absence (lanes 1 and 7) or in the presence of $20 \mathrm{nM}$ EGF for 1 (lanes 2 and 8), 3 (lanes 3 and 9), 5 (lanes 4 and 10), 15 (lanes 5 and 11) and 30 (lanes 6 and 12) $\mathrm{min}$ at $37^{\circ} \mathrm{C}$. In both cases, whole cell detergent extracts were prepared and were immunoprecipitated with a C3G antibody. The C3G immunoprecipitates were immunoblotted with a CrkII antibody (lanes 1-6) or a C3G antibody (lanes 7-12). Reprinted from reference [56].

stimulation, there was a time-dependent decrease in the amount of CrkII that could be coimmunoprecipitated with C3G (Fig. 2A, lanes 1-6). The dissociation of CrkII from C3G was detectable as early as $1 \mathrm{~min}$ and was maximal between 3 to 5 min (Fig. 2A, lanes 3 and 4). The insulinstimulated decrease of C3G immunoprecipitated CrkII protein was not due to differences in C3G immunoprecipitation as assessed by C3G immunoblotting of the C3G immunoprecipitates (Fig. 2A, lanes 7-12).

Similarly, activation of the EGF receptor also resulted in a rapid dissociation of the CrkII-C3G complex (Fig. 2B, lanes 1-6). The time-dependent uncoupling of CrkII from C3G was similar to insulin with detectable dissociation following $1 \mathrm{~min}$ of EGF treatment (Fig. 2B, lane 2). The maximal EGF-stimulated dissociation of the CrkII-C3G complex occurred between 3 to $5 \mathrm{~min}$ and was persistent for up to $30 \mathrm{~min}$ (Fig. 2B, lanes 3-6). As a control for immunoprecipitation, immunoblotting with the C3G antibody demonstrated equivalent amounts of immunoprecipitated C3G protein under each condition (Fig. 2B, lanes 7-12). These data are consistent with the CrkII-C3G complex functioning to maintain Rap1 in the active GTPbound state. However, the dissociation of the CrkII from C3G complex terminates this activation signal, thus allowing Rap1 to convert to the inactive GDPbound state.

The tyrosine kinase receptor mediated dissociation of the CrkII-C3G complex was also temporally correlated with an apparent conformational change and/or masking of Rap immunoreactivity [56]. Together, these data provide for a compelling model in which growth factor activation leads to the simultaneous activation of Ras and inactivation of Rap through the control of the guanylnucleotide exchange factors SOS and C3G (Fig. 3). In this model we propose 
that initially, Raf1 is maintained in an inactive state due to its association with Rap. Receptor tyrosine kinase activation results in the assembly and/or activation of the Shc-Grb2-SOS complex which then induces the exchange of GDP for GTP on Ras. At the same time, CrkII undergoes tyrosine phosphorylation which induces the dissociation of the CrkII-C3G complex. The uncoupling CrkII from C3G allows conversion of Rap from the active GTPbound conformational state to the inactive GDP form. The inactivation of Rap releases the bound Raf1 which can then associate with the active GTPbound Ras resulting in activation of the Raf1 serine kinase. The subsequent Raf1 dependent phosphorylation and activation of MEK results in phosphorylation and activation of ERK required for the downstream stimulation of various transcriptional and translational events. However, following MEK and/or ERK activation there is a feedback serine/threonine phosphorylation on SOS. This later event induces the dissociation of the Grb2-SOS complex terminating the Ras activation signal. Based upon the critical role of the Raf/ MEK/ERK pathway in controlling the relative balance between apoptosis and mitogenesis, this yin-yang model provides for a highly tuned mechanism that can tightly maintain these activities within normal physiological limits.

\section{References}

1. Bourne HR, Sanders DA, McCormick F (1991) The GTPase superfamily: Conserved structure and molecular mechanism. Nature 349: 117-127.

2. Bourne HR, Sanders DA, McCormick F (1990) The GTPase superfamily: A conserved switch for diverse cell functions. Nature 348: 125-132.

3. Capon DJ, Seeburg PH, McGrath JP, Hayflick JS, Edman U, Levinson AD, Goeddel DV (1983) Activation of Ki-ras2 gene in human colon and lung carcinomas by two different point mutations. Nature 304: 507-513.

4. Parada LF, Tabin CJ, Shih C, Weinberg RA (1982) Human EJ bladder carcinoma oncogene is homologue of Harvey sarcoma virus ras gene. Nature 297: 474-478.

5. McCoy MS, Toole JJ, Cunningham JM, Chang EH, Lowy DR, Weinberg RA (1983) Characterization of a human colon/lung carcinoma oncogene. Nature 302: 79-81.

6. Moodie SA, Willumsen BM, Weber MJ, Wolfman A (1993) Complexes of Ras GTP with Raf-1 and mitogen-activated protein kinase kinase. Science 260: 1658-1661.

7. Van Aelst L, Barr M, Marcus S, Polverino A, Wigler M (1993) Complex formation between Ras and Raf and other protein kinases. Proc Natl Acad Sci USA 90: 6213-6217.

8. Vojtek AB, Hollenberg SM, Cooper JA (1993) Mammalian Ras interacts directly with the serine/ threonine kinase Raf. Cell 74: 205-214.

9. Warne PH, Viciana PR, Downward J (1993) Direct interaction of Ras and the amino-terminal region of Raf-1 in vitro. Nature 364: 352-355.

10. Zhang X-F, Settleman J, Kyriakis JM, TakeuchiSuzuki E, Elledge SJ, Marshall MS, Bruder JT, Rapp UR, Avruch J (1993) Normal and oncogenic p21 ras proteins bind to the amino-terminal regulatory domain of c-Raf-1. Nature 364: 308-313.

11. Dent P, Haser W, Haystead TAJ, Vincent LA, Roberts TM, Sturgill TW (1992) Activation of mitogen-activated protein kinase kinase by v-Raf in NIH 3T3 cells and in vitro. Science 257: 14041407.

12. Howe LR, Leevers SJ, Gomez N, Nakielny S, Cohen P, Marshall CJ (1992) Activation of the MAP kinase pathway by the protein kinase raf. Cell 71: 335-342.

13. Kyriakis JM, App $\mathrm{H}$, Zhang $X$, Banerjee $\mathrm{P}$, Brautigan DL, Rapp UR, Avruch J (1992) Raf-1 activates MAP kinase-kinase. Nature 358: 417-421.

14. Zheng C-F, Guan K-L (1994) Activation of MEK family kinases required phosphorylation of two conserved ser/thr residues. EMBO J 13: 1123-1131.

15. Huang WD, Alessandrini A, Crews CM, Erikson RL (1993) Raf-1 forms a stable complex with mek1 and activates mek1 by serine phosphorylation. Proc Natl Acad Sci USA 90: 10947-10951.

16. Avruch J, Zhang X, and Kyriakis J (1994) Raf meets Ras: Completing the framework of a signal transduction pathway. Trends Biochem Sci 19: 279283.

17. Blenis J (1993) Signal transduction via the MAP kinases: Proceed at your own RSK. Proc Natl Acad Sci USA 90: 5889-5892.

18. Hill CS, Treisman R (1995) Transcriptional regulation by extracellular signals: mechanisms and specificity. Cell 80: 199-211.

19. Davis RJ (1993) The mitogen-activated protein kinase signal transduction pathway. J Biol Chem 268: 14553-14556.

20. Kitayama $H$, Sugimoto $Y$, Matsuzaki T, Ikawa $Y$, Noda M (1989) A ras-related gene with transformation suppresser activity. Cell 56: 77-84. 
21. Pizon V, Chardin P, Lerosey I, Olofsson B, Tavitian A (1988) Human cDNAs rap1 and rap2 homologous to the Drosophila gene Dras3 encode proteins closely related to ras in the 'effector' region. Oncogene 3: 201-204.

22. Jelink MA, Hassell JA (1992) Reversion of middle $\mathrm{T}$ antigen-transformed rat- 2 cell by Krev-1 implications for the role of p21c-ras in polyomavirus-mediated transformation. Oncogene 7: 1687-1698.

23. Campa MJ, Chang KJ, Molina y Vedia L, Reep BR, Lapetina EG (1991) Inhibition of Ras-induced germinal vesicle breakdown in Xenopus oocytes by Rap-1B. Biochem Biophys Res Commun 174: 1-5.

24. Cook S, Rubinfeld B, Albert I, McCormick F (1993) RapV12 antagonizes Ras-dependent activation of ERK1 and ERK2 by LPA and EGF in Rat 1 fibroblasts. EMBO J 12: 3475-3485.

25. Sakoda T, Kaibuchi K, Kishi K, Kishida S, Doi K, Hoshino M, Hattori S, Takai Y (1992) smg/rap1/ Krev-1 p21s inhibit the signal pathway to the c-fos promoter/enhancer from c-Ki-ras p21 but not from c-raf-1 kinase in NIH3T3 cells. Oncogene 7: 17051711.

26. Yatani A, Quilliam LA, Brown AM, Bokoch GM (1990) Rap1A antagonizes the ability of Ras and Ras-Gap to inhibit muscarinic $\mathrm{K}+$ channels. J Biol Chem 266: 22222-22226.

27. Zhang K, Noda M, Vass WC, Papageorge AG, Lowy DR (1990) Identification of small clusters of divergent amino acids that mediate the opposing effects of ras and Krev-1. Science 249: 162-165.

28. Frech M, John J, Pizon V, Chardin P, Tavitian A, Clark R, McCormick F, Wittinghofer A (1990) Inhibition of GTPase activating protein stimulation of ras-p21 GTPase by the Krev-1 gene product. Science 249: 169-171.

29. Hata Y, Kikuchi A, Sasaki T, Schaber MD, Gibbs JB, Takai Y (1990) Inhibition of the ras p21 GTPaseactivating protein-stimulated GTPase activity of c-Ha-ras p21 by smg p21 having the same putative effector domain as ras p21s. J Cell Biol 265: 71047107.

30. Nassar N, Horn G, Herrmann C, Scherer A, McCormick F, Wittinghofer A (1995) The 2.2 angstrom crystal structure of the Ras-binding domain of the serine/threonine kinase c-Raf1 in complex with Rap1A and a GTP-analogue. Nature 375: 554-560.

31. Spaargaren M, Bischoff JR (1994) Identification of the guanine nucleotide dissociation stimulator for Ral as a putative effector molecule of R-ras, H-ras, K-ras and rap. Proc Natl Acad Sci USA 91: 1260912613.

32. Vossler MR, Yao H, York RD, Pan M-G, Rim CS, Stork PJS (1997) cAMP activates MAP kinase and Elk-1 through a B-Raf- and Rap1-dependent pathway. Cell 89: 73-82.

33. Quilliam LA, Huff SY, Rabun KM, Wei W, Park W, Broek D, Der CJ (1994) Membrane-targeting potentiates guanine nucleotide exchange factor CDC25 and SOS1 activation of ras transforming activity. Proc Natl Acad Sci USA 91: 8512-8516.

34. Aronheim A, Engelberg D, Li N, Al-Alawi N, Schlessinger J, Karin M (1994) Membrane targeting of the nucleotide exchange factor Sos is sufficient for activating the Ras signaling pathway. Cell 78: 949-961.

35. McCollam L, Bonfini L, Karlovich CA, Banerjee U, Czech MP (1995) Functional roles for the pleckstrin and Dbl homology regions in the ras exchange factor son-of-sevenless. J Biol Chem 270: 1595415957.

36. Karlovich CA, Bonfini L, McCollam L, Rogge RD, Daga A, Czech MP, Banerjee U (1995) In vivo functional analysis of the Ras exchange factor Son of sevenless. Science 268: 576-579.

37. Chardin P, Camonis JH, Gale NW, van Aelst L, Schlessinger J, Wigler MH, Bar-Sagi D (1993) Human SOS1: A guanine nucleotide exchange factor for Ras that binds to GRB2. Science 260: 1338-1343.

38. Gale NW, Kaplan S, Lowenstein EJ, Schlessinger J, Bar-Sagi D (1993) Grb2 mediates the EGFdependent activation of guanine nucleotide exchange on Ras. Nature 363: 88-92.

39. Li N, Batzer A, Daly R, Yajnik V, Skolnik EY, Chardin P, Bar-Sagi D, Margolis B, Schlessinger J (1993) Guanine-nucleotide-releasing factor hSos1 binds to Grb2 and links receptor tyrosine kinases to Ras signalling. Nature 363: 85-88.

40. Lowenstein EJ, Daly RJ, Batzer AG, Li W, Margolis B, Lammers R, Ullrich A, Skolnik EY, Bar-Sagi D, Schlessinger J (1992) The SH2 and SH3 domaincontaining protein Grb2 links receptor tyrosine kinases to ras signaling. Cell 70: 431-442.

41. Rozakis-Adcock M, Fernley R, Wade J, Pawson T, Bowtell D (1993) The SH2 and SH3 domains of mammalian Grb2 couple the EGF receptor to the Ras activator mSOS1. Nature 363: 83-85.

42. Skolnik E, Batzer A, Li N, Lee C-H, Lowenstein E, Mohammadi M, Margolis B, Schlessinger J (1993) The function of Grb2 in linking the insulin receptor to Ras signaling pathways. Science 260: 1953-1955.

43. Gotoh T, Hattori S, Nakamura S, Kitayama H, Noda M, Takai Y, Kaibuchi K, Matsui H, Hatase O, Takahashi H, Kurata T, Matsuda M (1995) Identification of Rap1 as a target for the Crk SH3 domain-binding guanine nucleotide-releasing factor C3G. Mol Cell Biol 15: 6746-6753.

44. Tanaka S, Morishita T, Hashimoto Y, Hattori S, Nakamura S, Shibuya M, Matuoka K, Takenawa T, Kurata T, Nagashima K, Matsuda M (1994) C3G, a guanine nucleotide-releasing protein expressed ubiquitously, binds to the SRC homology-3 domains 
of CRK and GRB2/ASH proteins. Proc Natl Acad Sci USA 91: 3443-3447.

45. Feller SM, Knudsen B, Hanafusa H (1995) Cellular proteins binding to the first src homology 3 (SH3) domain of the proto-oncogene product c-Crk indicate Crk-specific signaling pathways. Oncogene 10: 1465-1473.

46. Knudsen BS, Feller SM, Hanafusa H (1994) Four proline-rich sequences of the guanine-nucleotide exchange factor $\mathrm{C} 3 \mathrm{G}$ bind with unique specificity to the first Src homology 3 domain of Crk. J Biol Chem 269: 32781-32787.

47. Matsuda M, Tanaka S, Nagata S, Kojima A, Kurata T, Shibuya M (1992) Two species of human CRK cDNA encode proteins with distinct biological activities. Mol Cell Biol 12: 3482-3489.

48. Mayer BJ, Hamaguchi M, Hanafusa H (1988) A novel viral oncogene with structural similarity to phospholipase C. Nature 332: 272-275.

49. Reichman CT, Mayer BJ, Keshau S, Hanafusa H (1992) The product of the cellular crk gene consists primarily of $\mathrm{SH} 2$ and $\mathrm{SH} 3$ regions. Cell Growth Differ 3: 451-460.

50. ten Hoeve J, Kaartinen V, Fioretos T, Haataja L, Voncken JW, Heisterkamp N, Groffen J (1994) Cellular interactions of CRKL, and $\mathrm{SH} 2-\mathrm{SH} 3$ adaptor protein. Cancer Res 54: 2563-2567.

51. Matsuda M, Hashimoto $Y$, Muroya K, Hasegawa H, Kurata T, Tanaka S, Nakamura S, Hattori S (1994) CRK protein binds to two guanine nucleotidereleasing proteins for the ras family and modulates nerve growth factor-induced activation of ras in PC12 cells. Mol Cell Biol 14: 5495-5500.

52. Cherniack A, Klarlund J, Conway B, Czech M (1995) Disassembly of son-of-sevenless proteins from Grb2 during p21(ras) desensitization by insulin. J Biol Chem 270: 1485-1488.

53. Holt K, Kasson B, Pessin J (1996) Insulin stimulation of a MEK-dependent but ERK-independent SOS protein kinase. Mol Cell Biol 16: 577-583.

54. Langlois W, Sasaoka T, Saltiel A, Olefsky J (1995) Negative feedback regulation and desensitization of insulin- and epidermal growth factor-stimulated p21 ras activation. J Biol Chem 270: 25320-25323.

55. Waters S, Holt KH, Ross SE, Syu L-J, Guan K-L, Saltiel A, Koretzky G, Pessin J (1995) Desensitization of Ras activation by a feedback disassociation of the Sos-Grb2 complex. J Biol Chem 270: 20883-20886.

56. Okada S, and Pessin JE (1997) Insulin and epidermal growth factor stimulate a conformational change in Rap1 and dissociation of the CrkII-C3G complex. J Biol Chem 272: 28179-28182. 